\title{
Spatial convergence and growth in Indian agriculture: 1967-2010
}

Tirtha Chaterjee

Indira Gandhi Institute of Development Research, Mumbai September 2014 http://www.igidr.ac.in/pdf/publication/WP-2014-035.pdf 


\title{
Spatial convergence and growth in Indian agriculture: 1967-2010
}

\author{
Tirtha Chaterjee \\ Indira Gandhi Institute of Development Research (IGIDR) \\ General Arun Kumar Vaidya Marg \\ Goregaon (E), Mumbai- 400065, INDIA \\ Email(corresponding author): tirtha@igidr.ac.in
}

\begin{abstract}
Inter-state diversity has been a perennial feature of Indian agriculture. The study probes if per capita income in Indian agriculture has converged across states in the last four and a half decades. It finds strong evidence in favour of beta convergence but not in favour of sigma convergence. Spatial econometric techniques used in the study aid in identifying the impact of spatial neighbours on the growth of a state. Results indicate significant spatial dependence among states. The study also identifies the drivers of growth agriculture in the last four and a half decades and results indicate that infrastructure like roads, irrigation, electricity aid in growth and so do quality of human capital. Hence, investments targeting higher quality of infrastructure, both physical and human and efficient water management will aid in agricultural growth in India.
\end{abstract}

Keywords: Agriculture, growth, regional convergence, spatial dependence

JEL Code: O13, O18, R12, R15

\section{Acknowledgements:}

Author is grateful to Prof. A. Ganesh Kumar for his valuable comments and sugestions. 


\section{Spatial convergence and growth in Indian agriculture: 1967-2010}

\section{Tirtha Chatterjee ${ }^{\mathrm{a}}$}

Inter-state diversity has been a perennial feature of Indian agriculture. The study probes if per capita income from agriculture has converged across states and finds evidence in favour of beta convergence. Spatial econometric techniques used indicate significant spatial dependence in agricultural growth. Infrastructure like roads, irrigation, and electricity, diversification in cropping pattern and quality of human capital are found to aid in growth. However, excessive rainfall tends to decrease growth rate in India. The spill-over across states are found to be primarily driven by roads, irrigation and rural literacy and we also find significant impact of spatial income growth providing evidence in favour of agglomeration effects. Hence, investments in human capital, physical infrastructure specially water management and incentives towards growing crops which yield higher returns will aid agriculture growth in India.

Keywords: Agriculture, growth, regional convergence, spatial dependence

JEL Codes: $O 13, O 18, R 12, R 15$

Acknowledgements: This study is a part of author's PhD. research work at Indira Gandhi Institute of Research and Development, Mumbai, India. Author is extremely grateful to Prof. A. Ganesh Kumar for his guidance, suggestions and comments.

a: Doctoral research student, Indira Gandhi Institute of Development Research, IGIDR, Mumbai 


\section{Introduction}

Inter-state disparity has been an enduring feature of Indian agriculture. States perform differently from one another potentially because of differentials in agro-ecological conditions, cropping pattern, input usage, infrastructural support etc. It is widely accepted that agricultural growth is hugely dependent on agro-climatic conditions of a region. A state with favourable agro-climatic condition will have an upper hand in agriculture production and hence have higher chance of generating more income from the same. However, advancement in technology, investments aiding growth in infrastructure and input use and other state level policies can help a state initially un-favourably endowed, to perform better than it would have been in their absence. Reducing inter-state disparity has been one of the primary developmental concerns of policy makers in India. Research studies in Indian context (for example Bhide, Kalirajan and Shand, 1998; Chand and Chauhan, 1999; Mukherjee and Koruda, 2003; Ghosh, 2006, Somashekharan, Prasad and Roy, 2011 and Mukhopadhyay and Sarkar, 2014) indicate that the level and pattern of inter-state disparity depends on the variables used to study disparity, time period of the study and results have also been different for the same variable over different phases of time.

However, all the studies on disparity in Indian context have ignored the role of geographical dependence on agricultural growth. Spatial dependence plays an important role in agriculture performance. The underlying idea is that forces driving state-level agricultural performance could exhibit significant geographical dependence because of agro-climatic zones being spread over multiple states, spill-over of information and technology and trade and transportation infrastructure into neighbouring regions etc. Figure 1 indicates that over the years both level and annual growth rate of Net State Domestic Product (NSDP) per rural person seem to exhibit a spatial pattern ${ }^{1}$. States which are geographically contiguous also belong to the same income/growth quantile. Studies like Bhalla and Singh, 1997 have pointed

\footnotetext{
${ }^{1}$ These specific years have been chosen because of the way the sub-periods have been defined later in the text for the analysis.
} 
towards geographical concentration of agricultural performance but none of the studies ${ }^{2}$ have empirically estimated the impact of inherent spatial dependence in income growth from Indian agriculture.

\section{[Figure 1]}

This study aims to fill this gap in literature on Indian agriculture and examines spatial convergence across states in per capita income from agriculture. It identifies the drivers of growth of per capita income and tests if differences in the same across $17^{3}$ major states of India have narrowed down over the period from 1967-68 to 2010-11. The methodology used for the study is drawn from Barro and Sala-I-Martin, 1992 and spatial econometrics literature (Anselin, 1988, Elhorst, 2003). The analysis has been done at the state level because of paucity of a rich data set for such a long time span at a lower level of geographical aggregation for example districts although spatial dependence is expected to be stronger at a lower level of geographical aggregation.

Classical sigma and beta convergence measures have been typically used in literature to analyse the disparity in income across regions. Sigma convergence $(\sigma)$ method analyzes the cross sectional dispersion of per- capita incomes across economies and is measured by the standard deviation of the logarithm of per capita incomes. Beta convergence measures tests the underlying idea that initially poorer region possibly tends to catch up with the rich ones. Econometrically, beta convergence tests are estimated through two methods, unconditional and conditional. Unconditional beta convergence $(\beta)$ approach estimates the relation between average growth rates of per capita income over a time period and the level of income at the initial period, irrespective of the state specific characteristics. When the same estimation is performed after controlling the structural characteristics of the regions, it is called conditional beta convergence. According to the neo-classical growth model, inverse relation between growth and income indicates convergence and is a consequence of diminishing returns to capital accumulation.

\footnotetext{
${ }^{2}$ In the context of Indian agriculture, only Jones and Sen (2006) have used spatial econometrics to study the relation between land productivity and poverty and found statistically significant spatial dependence across states.

${ }^{3}$ These 17 states contribute more than $96 \%$ of the national Net Domestic Product (NDP) from agriculture. The states are Andhra Pradesh (AP), Assam, Bihar+Jharkhand, Gujarat, Haryana, Himachal Pradesh (HP), Jammu \& Kashmir (JK), Karnataka, Kerala, Maharashtra, Madhya Pradesh +Chhattisgarh (MP), Orissa, Punjab, Rajasthan, Tamil Nadu (TN), Uttar Pradesh+ Uttarakhand (UP) and West Bengal (WB)
} 
However, here, each region is assumed to be an independent and isolated unit. But in reality, they are not isolated 'absolute' units. Econometrically, controlling 'absolute' location in estimation implies that the impact of being located at a particular point in space is being controlled by region dummies or fixed effect estimation techniques whereas incorporating 'relative" location in estimation technique implies that the effect of being located closer or farther away from specific regions is being controlled. This is done through spatial weight matrices which help in quantifying the spatial relations across regions and the same are used in estimation techniques. One of the contributions of this study is use of two alternative spatial weight matrices, viz., length of borders shared by the states and number of contiguous districts in each state, in addition to using the conventional contiguity and inverse distance based spatial weight matrices used in literature. The idea behind using district based (or length of shared borders based) matrix is to quantify the difference among contiguous states by assigning higher weights to states with higher number of contiguous districts (higher length of shared borders) compared to those with lower number of contiguous districts (shared border length).The empirical results (discussed later) in this study provide evidence in favour of these spatial weight criteria compared to contiguity based matrices which give a uniform weight to all the contiguous states.

The rest of the paper is organized as follows: The next section briefly describes the methodology adopted and data used in the study. The growth performance of the states from 1967-68 to 2010-11 have been compared and spatial patterns discussed in section 3. Section 4 reports the results of the analysis while section 5 provides some concluding remarks.

\section{Methodology and data used}

As discussed, the two commonly used approaches to test income convergence in literature are sigma and beta convergence. Sigma convergence refers to reduction in dispersion in the levels of income across regions over time. Beta convergence estimation is based on a log-linear approximation around the steady

\footnotetext{
${ }^{4}$ For details on absolute and relative location, refer Abreu, De Groot and Florax (2005).
} 
state of a Solow type growth model. In this approach, an empirical relationship between the initial income level in a region and the subsequent growth rate is estimated. A positive association shows high growth rate for richer economies and hence a divergent growth scenario while a negative relationship indicates convergence i.e. that poorer regions are growing faster than the richer ones and hence is evidence in favour of "catching up" by the poorer states. Neoclassical growth model predicts that regional incomes will overtime converge to their respective steady states, which depends on savings rate, population growth rate and rate of technological progress in a region, which are assumed exogenous in the model. Therefore, the exogenous rates at which all the factors of production in an economy grow, determine the long run steady rate of growth of the economy.

Studies like Quah, 1993, a, b; Barro and Sala-I-Martin, 1992 Young, 2008 have acknowledged that beta convergence is not a sufficient condition for sigma convergence. Sala-I-Martin (1994) suggests that beta convergence measure is more interesting concept since it responds to questions, such as, whether poor economies (countries or regions) are predicted to grow faster than rich ones, how fast the convergence process is, whether the convergence process is conditional or unconditional and whether there is a different convergence process between groups of economies with different structures. However, Quah, 1993a suggests that sigma convergence is of greater interest since it speaks directly as to whether the distribution of income across economies is becoming more equitable. Additionally, Quah, 1993b shows that a negative relationship between growth rates and initial values do not indicate a reduction in crosssectional variance and it is also possible to observe a diverging distribution (sigma dispersion) in presence of such negative relationship. Given that there is no general consensus on this issue, in this study, both approaches have been used to analyze convergence across states in Indian agriculture. Additionally, spatial dependence among states has also been controlled in the estimation of beta convergence.

Spatial dependence is said to occur when observations of a particular spatial unit is dependent on observations of its neighbours. It implies that there exists a relationship between what happens at different points in space. Econometrically, spatial dependence is quantified through spatial matrix $(W)$. ' $W$ ' is a 
symmetric matrix and can be defined on the basis of context of the study. By convention, the diagonal elements are set to zero, $w_{i i}=0$. However, any form must satisfy two basic rules of being finite and nonnegative (Anselin, 1988). In the simplest case, the weights are defined on the basis of contiguity i.e. regions are assigned 'one' in the matrix if they share borders and 'zero' otherwise.

We have used and compared four spatial weight matrices namely, state-contiguity based, inverse-distance based, shared border based and district-contiguity based matrices. In case of state-contiguity based matrices, weight 'one' implies that states are contiguous to one another and 'zero' implies that they are not. In case of inverse-distance based matrix, inverse of the Euclidean distance between the geographical centroid of two states is used as the weight. This weighing scheme ensures that higher weight is given to states which are closer to each other and vice-versa. In case of length of border based spatial weight scheme, weights are assigned according to the length of the border shared between two states. The idea behind using length of shared borders between states is that spatial spill-over is expected to be proportional to the possibility of connectivity between two states which is more for states with higher length of shared borders. If a state has two neighbours, one with a higher shared border length compared to the other, rather than giving a uniform weight to both the contiguous states, higher weight to the first state with higher shared border length will ensure that incorporated spatial effects are proportional to the possibility of spatial spill-over.

In case of contiguous-district based spatial scheme, weight is assigned according to the total number of contiguous districts between two states. The idea behind using districts based spatial weight matrix is again to control spatial effects in a manner that they are proportional to the possibility of spatial spillover. States in India are spread across diverse agro-ecological zones and hence controlling state level contiguity does not guarantee that spatial dependence is completely incorporated. Quite often districts within a state are more homogeneous to contiguous districts in the neighbouring states than noncontiguous districts of the same state. For example eastern and western parts of the state of Uttar Pradesh fall under different agro-ecological zone, while eastern part is similar to eastern state of Bihar, western 
part is similar to northern state of Himachal Pradesh. Hence, giving a uniform weight of 'one' to both Bihar and Himachal Pradesh will not correctly quantify the spatial dependence. This district based matrix will give a higher weight to states with which Uttar Pradesh has more number of contiguous districts. Although this does not ensure that spatial dependence is completely controlled, it is an improvement over basic state level contiguity. All the matrices have been row standardized. ${ }^{5}$

Spatial dependence is typically detected using Global and local Moran's I tests. If these tests reject the null of absence of spatial dependence, then spatial modelling should be used to explain the behaviour of the data. Global Moran's I test statistics for the presence of global spatial dependence among the spatial units is given by:

$$
I=\frac{n}{\sum_{i} \sum_{j} w_{i j}} \frac{\sum_{i=1}^{n} \sum_{j=1}^{n} w_{i j}\left(x_{i}-\bar{x}\right)\left(x_{j}-\bar{x}\right)}{\sum_{i=1}^{n}\left(x_{i}-\bar{x}\right)^{2}}(1)
$$

Where $\mathrm{n}$ is the number of regions, $w_{i j}$ is the element of the weight matrix $W, x_{i}$ is the value of the variable at region $i$ and $\bar{x}$ is the cross-sectional mean of $x$. A significant correlation statistic indicates presence of spatial dependence. However, these global tests overlook the local spatial dependence. It is possible that for a given year global spatial detection tests indicate no spatial relation while local spatial tests indicate strong dependence across some regions in the total set of regions. Hence, to have a better idea on local spatial dependence, local Moran's I tests are used. For each location, these values compute its similarity with its neighbours and test whether the similarity is statistically significant.

For each location, local Moran's I test statistic can be computed and this is given by

$$
I_{i}=\frac{\left(x_{i}-\bar{x}\right) \sum_{j} w_{i j}\left(x_{j}-\bar{x}\right)}{\sum_{i}\left(x_{i}-\bar{x}\right)^{2} / n}(2)
$$

Under the null hypothesis of no spatial dependence, both the global and Local Moran's I test statistic asymptotically follow a standard normal distribution.

\footnotetext{
${ }^{5}$ Lesage and Pace (2009)
} 
Once, spatial dependence is detected, relationships across spatial units are incorporated in the estimation strategy. There can be three types of spatial relation: (1) spatial dependence in dependent variable i.e. spatial lag model, (2) spatial dependence in error i.e. spatial error model and (3) spatial dependence in explanatory variables i.e. spatial Durbin model. A full model in a panel framework, once all types of spatial interactions are incorporated will be as follows:

$$
\begin{gathered}
Y_{i, t}=\eta_{i}+\rho Y^{*}{ }_{i, t}+\alpha+X_{i, t} \beta+X^{*}{ }_{i, t} \theta+u_{i, t} \\
u_{i, t}=\lambda u^{*}{ }_{i, t}+\varepsilon_{i, t}
\end{gathered}
$$

where the variable $Y^{*}=W Y$ captures the spatial dependence among the dependent variables, $X^{*}=W X$ the spatial effects among the independent variables, and $u^{*}=W u$ the spatial effects among the disturbance terms of the different units, $\boldsymbol{\rho}$ is called the spatial autoregressive coefficient, $\lambda$, the spatial autocorrelation coefficient, while $\boldsymbol{\theta}$, just as $\boldsymbol{\beta}$, represents a $K \times 1$ vector of fixed but unknown parameters. $W$ is a nonnegative $N \times N$ spatial weights matrix of known constants representing the spatial arrangement of the units in the sample.

However, if all three forms of spatial interaction effects are estimated simultaneously, then it is not possible to distinguish and identify one from another (Lee and Yu, 2010). According to Lesage and Pace (2009), the cost of ignoring spatial dependence in the dependent variable and/or in the independent variables is relatively high because of omitted variable bias and the estimator of the coefficients for the remaining variables is biased and inconsistent. In contrast, ignoring significant spatial dependence in the disturbances will only cause a loss of efficiency. Elhorst (2012) suggests that the best option to estimate a spatial model is to exclude the spatially auto correlated error term and to consider a model with spatial interaction effects in dependent and explanatory variables (Spatial Durbin model). Both Anselin (1988) and Lesage (2009) show that least squares estimators, if used in case of models with spatially lagged dependent variables lead to biased and inconsistent estimates. They recommend the use of maximum likelihood estimation techniques to estimate the coefficients of the model. In panel data framework, Lee 
and $\mathrm{Yu}$ (2010) show that the maximum likelihood estimator of the spatial lag and of the spatial error model with spatial fixed effects, as set out in Elhorst (2003, 2010), will yield inconsistent estimates of all parameters of the spatial lag and of the spatial error model with spatial and time-period fixed effects. To correct this, they propose a simple bias correction procedure based on the parameter estimates of the uncorrected approach. Panel data suffers from initial values problem and this is controlled through dynamic panel models where the lagged value of the dependent variable is also used as an additional explanatory variable. This corrects the autocorrelation problem in panel data models (Wooldridge (2005), Pfaffermayr (2012)).

Hence, in this study, spatial dynamic conditional beta convergence and sigma convergence across states in income from agriculture has been explored for 17 states in India from 1967-68 to 2010-11. The only consistent state level data available on income from agriculture for states in India from 1967 onwards is net state domestic product (NSDP) from agriculture. Data source for the same is EPWRF Income (NSDP) is measured at constant (2004-05) prices. Rural population data from CENSUS has been used to compute NSDP per rural person. The newly formed states of Jharkhand, Chhattisgarh and Uttaranchal have been clubbed together with their parent states of Bihar, Madhya Pradesh and Uttar Pradesh respectively to maintain uniformity in the panel data set. For purpose of analysis, the time period from 1967-68 to 201011 has been divided into following three sub phases on the basis of changing policies in agriculture sector. This aids in better understanding of the changing pattern of growth of agricultural income in India.

- $\quad 1^{\text {st }}$ sub-phase : 1967-1977: the period of green revolution

- $\quad 2^{\text {nd }}$ sub-phase: 1978-1989: period of falling public investment in agriculture

- $\quad 3^{\text {rd }}$ sub-phase: 1990-2010: period of economic reforms

Figure 2 plots the shares of public investments i.e. share of gross fixed capital formation (agriculture) in GDP from agriculture (both at constant 2004-05 prices). Investments were higher in the latter half of 1960s (sub phase 1 in our study) compared to the beginning of 1980s. The 1980s and 1990s are 
characterized with low levels of public investment in agriculture. One can however see a rising trend in late 1990 s and early $2000 s^{6}$.

[Figure 2]

Following other studies on Indian agriculture (like Fan et al, 2000, Binswanger, 1993), we have controlled for state level inputs, infrastructure status, rainfall etc. to estimate the role of state itself on its growth and additionally spatially weighted variables have been used to estimate the role of the neighbouring states on its growth.

Among inputs we control for land, tractors, fertilizer and livestock as inputs in agriculture. The annual data on land use is available in "Land use statistics, Department of economics and statistics, ministry of agriculture". Data for number of tractors was obtained from quinquennial livestock Census which is conducted by Department of animal husbandry, dairying and fishing, Government of India. The data has been interpolated using compound growth rate to get a panel data set on tractors used from these quinquennial surveys. Fertilizer use has been defined as total fertilizer (Nitrogen+Phophate+Potassium) consumed in kilograms per unit total cropped area. The data for fertilizer consumed is available state-wise and annually from "Fertilizer Statistics". Livestock has been defined as number of livestock per unit total area of the state. Data for number of livestock in total and also number of cattle, buffaloes, goats and sheep was collected from quinquennial livestock census conducted by conducted by Department of animal husbandry, dairying and fishing, Government of India. The data from these quinquennial surveys has been interpolated using compound growth rate to get a panel data set on total livestock and its types. Infrastructure and other state level characteristics have been controlled through road quality, irrigation, electricity, state expenditure on agriculture and cropping patterns. Road quality is defined as a ratio of total surfaced road length to total road length (both in kms.) in the state. The state-wise annual data on total road length and surfaced road length was collected from "Basic Road Statistics" and "Statistical

\footnotetext{
${ }^{6}$ The rise in share of gross fixed capital in the $3^{\text {rd }}$ phase has been controlled in the study through year dummies as number of years post rise in investment was very low to accommodate a separate phase and perform a robust statistical analysis.
} 
abstracts of India". Electricity is defined as percentage of villages electrified. Annual state-wise data for the same was obtained from EPRWF database. A dummy variable with value equal to 'one' when less than 100 per cent villages have been electrified and 'zero' if 100 per cent villages are electrified. Irrigation is defined as share of gross area irrigated in total cropped area. State-wise annual data on gross area irrigated and total cropped area from "Land use statistics, Department of Economics and Statistics, Ministry of Agriculture". State expenditure on agriculture is defined as state expenditure in agriculture per unit sq. km. area. ${ }^{7}$. State-wise annual data on expenditure was collected from "Finances of state government" published by RBI. Cropping pattern is defined as share of area under different crops. Statewise annual data was collected from "Area, Yield, Production of Principle Crops" by Ministry of Agriculture. Share of area under different groups of crops namely cereals, pulses, fibre, oilseeds, sugar and all other crops have been clubbed together as rest.

As other studies on Indian agriculture (Fan et al, 2000), rural literacy rate has been used as a proxy for quality of human capital. This is defined as percentage of literate rural persons in total rural population. Data on rural literacy rate was collected from CENSUS (various years). The years between two consecutive surveys were interpolated using assuming constant growth rates.

Rainfall has been controlled in such a manner that the impact of different levels of deviation of actual rainfall from the normal levels can be differentiated. Three rain dummies have been defined on the basis of absolute percentage deviation of actual average annual rainfall from normal average annual rainfall. The dummies are based on rain dummy_1 ='one' if percentage absolute deviation of rainfall from normal is between 5 and 10 per cent otherwise zero. Rain dummy_2 ='one' if percentage absolute deviation of rainfall from normal is between 10 and 20 per cent otherwise zero and rain dummy_3 ='one' if percentage deviation of actual average annual rainfall is between 20 and 100 otherwise zero. Average annual data on rainfall was collected from various publications of Statistical abstract of India.

\footnotetext{
${ }^{7}$ Expenditure on agriculture and allied activities include expenditure on crop husbandry, soil and water conservation, animal husbandry, dairy development, fisheries, forestry and wild life, plantations, food storage and warehousing, agriculture research and development, food and nutrition, community development and other agricultural programmes. Both revenue and capital expenditure have been included. This data is available from 1972.
} 
Spatially weighted variables have been constructed by weighing the neighbouring states using the different spatial weight matrices i.e. these newly created variables are the weighted means of observations of neighbouring states where the weights are used according to the spatial weight criteria in the models. Therefore, the conditional convergence equation using a spatial dynamic panel fixed effects model in a maximum likelihood framework used for the analysis can be written as:

$$
\begin{aligned}
\operatorname{growth}_{i t}=\ln ( & \left.y_{i, t}\right)-\ln \left(y_{i, t-1}\right) \\
& =\alpha_{i}+\beta \ln \left(y_{i, t-1}\right) \\
& + \text { growth }_{i, t-1}+\gamma_{1} \text { inputs }_{i t} \\
& +\gamma_{2} \text { infrastructure and other state level characteristics }_{i t}+\gamma_{3} \text { human capital }_{i, t} \\
& +\gamma_{4} \text { rainfall }_{i, t}+\gamma_{5} \text { spatial variables }_{i, t}+\in_{i, t}
\end{aligned}
$$

Here, coefficient of $\beta$ gives evidence in favour or against convergence across states $\alpha_{i}$ is the state specific effects and the impact of the other factors on growth can be obtained from coefficients $\gamma_{1}$ to $\gamma_{5}$.

\section{Growth performance across states}

Table 1, which gives the levels and growth of per capita NSDP at 2004-05 constant prices, brings out some interesting features on the regional pattern of agricultural growth in India. Taking the entire period, the all India annual compound growth rate of NSDP from agriculture at 2004-05 constant prices was 2.29 per cent. During this entire period, the highest growth rate was recorded by northern state of Punjab (4.78 per cent) while the lowest growing state was eastern state of Assam ( 0.50 per cent).The other states with high growth in the entire time period were Haryana in the north, Maharashtra and Gujarat in the west and West Bengal in the east. Apart for Assam, the states with low growth were Andhra Pradesh in the south and Uttar Pradesh in central India, JK and HP in the north. The coefficient of variation of growth rates across states in the entire time period was 39.26 per cent.

There were important changes in the regional growth pattern in the sub-phases. In sub-phase 1 (green revolution phase), growth rate of income from agriculture in India was 5.42 per cent. This period recorded 
the highest growth rate among all the sub-phases. However, this phase also recorded a high coefficient of variation across states (51.75 per cent). Growth rate was highest for Punjab (13.77 per cent) in north while it was lowest for Andhra Pradesh (0.32 per cent) in south. The other states with a high growth rate in this phase were Haryana in the north-west, Gujarat in the west and Bihar and West Bengal in the east. And the states with low growth rates were Andhra Pradesh and Tamil Nadu in the south, Assam in the east, Uttar Pradesh and Madhya Pradesh in central India.

In the $2^{\text {nd }}$ sub-phase, growth rate of agricultural income at the national level fell to 0.69 per cent. This was the phase with the lowest growth rates and highest disparity measured in terms of coefficient of variation (78 per cent). States like Bihar (-1.34 per cent), Jammu and Kashmir (-0.85 per cent) and Tamil Nadu (0.83 per cent) recorded a negative growth rate in this sub-phase. Growth rate of Orissa (4.62 per cent) was the highest while Bihar grew at the lowest rate. The states which performed better compared to the rest of the states were Orissa and West Bengal in east, Madhya Pradesh in central India, Punjab and Himachal Pradesh in the north while the states which performed the worst during the 1980s were Bihar in the east, Jammu and Kashmir in north, Tamil Nadu in south, Rajasthan and Gujarat in west.

The all India growth rate in the third sub-phase was 1.46 per cent and the coefficient of variation fell to 49.87 per cent. Maharashtra, Gujarat, Kerala, Andhra and TN grew at the highest rates while the states like Madhya Pradesh, Uttar Pradesh, Himachal Pradesh, Assam and Orissa grew at the lowest rate. Clearly, western and southern states were the best performers in this phase and eastern states performed the worst and had negative growth rates.

Hence, there is both evidence of rising spatial disparity across states and also of catching up in the sense that some of the states like Gujarat and Maharashtra in the west, which were comparatively poorly performing in earlier phases were recovering in the later sub-phases. This catching up process will be empirically tested using beta convergence estimation in the next section.

Table 1- growth performance across Indian states

Figure 3 plots the coefficient of variation (CV) of levels of per capita NSDP from agriculture and key infrastructure like roads, electricity, irrigation and state expenditure on agriculture across states from 1967 
to 2010 to have a better idea of pattern of inter-state disparity. All the key infrastructure and per capita income show a decline in CV in the 1970s (sub-phase 1). In sub-phase 2, the decline continues except for income and power. In sub-phase 3 however, CV increases for all except expenditure on agriculture and power consumption.

[Figure 3]

\section{Spatial dependence across states}

Spatial dependence has been empirically detected through local and global Moran's I indices using spatial weight matrices defined on the basis of state-contiguity based matrix, inverse-distance between two states, district-contiguous based matrix and length of borders shared between two states.

For contiguity based matrices, states which share borders are considered neighbours and assigned value 'one' while others (no borders shared) are not considered neighbours and are assigned 'zero weight in the matrix. For distance based matrix, weights are assigned on the basis of inverse distance (Euclidean distance between centroid of states) between the two states. In case of length of borders shared, weights are assigned on the basis of length of borders shared between a state pair. It equals 'zero' if no border is shared between the states. In case of contiguous districts based weight matrices, weights are assigned on the basis of total number of contiguous districts for each state pair and it is 'zero' if no districts are contiguous.

The results of global Moran's I computed have been given in Table 2 which shows that it is significant for all the weight structures from 1970. Moran's I result for significant years shows positive autocorrelation i.e. regions with similar levels of per-capita income were also geographically closer. The value of the Moran's I statistic can be interpreted as the level of spatial dependence ${ }^{8}$. Moran's I values for inverse distance based spatial weight matrices are the lowest compared to all other spatial weight matrices.

Table 2: Results of global Moran's test

\footnotetext{
${ }^{8}$ Rey and Montouri (1999).
} 
The plot of global Moran's I in Figure 4 shows that spatial dependence has declined from 1970 to 1990 but there is a turn-around since late 1990s after which there seems to be a positive trend in spatial dependence. But it was particularly high in early 70 s and 90 s.

[Figure 4]

While global Moran's I detects the aggregate spatial pattern, local Moran test (ANSELIN, 1995) detects local dependence and helps locate areas of strong spatial linkages. Local Moran's I for 1966 and 2010 are given in Table $3^{9}$. States have significant local spatial dependence in 1966 when there was no significant global spatial dependence.

Table 3-Results of Local Moran's test

States which had significant local spatial dependence for almost all the years were Northern states like Punjab, Haryana, Himachal Pradesh and Uttar Pradesh and eastern states like Bihar, West Bengal, Orissa, Assam, western states like Madhya Pradesh, Maharashtra, Rajasthan and Gujarat and Andhra Pradesh in south.

Thus, this preliminary analysis points towards the presence of spatial dependence across states in addition to high disparity in level and growth of income across states. Nevertheless one can also find some instances of catching up for the western states of Gujarat and Maharashtra. It provides an empirical basis to analyse the convergence behaviour of per capita income from agriculture taking into account this spatial dependence across states.

\section{Results}

\section{Sigma convergence}

Figure 5 which plots the standard deviation of log of NSDP per rural person from agriculture for the entire time shows evidence in favour of sigma convergence in phase 1 as it can be seen that standard

\footnotetext{
${ }^{9}$ Results of local Moran's I for other years have not been shown in the table owing to paucity of space. They can be shared on request
} 
deviation of income across states follows a declining trend only in phase 1 . However, we find evidence against sigma convergence in the later phases.

[Figure 5]

Figure 6 plots the global Moran's I statistics and standard deviation of log of per capita income over time for the full and different sub-periods. These plots point to a negative relationship between the two. Indeed, a simple correlation ${ }^{10}$ between standard deviation of log of income and global Moran's I statistic for all the spatial weight criteria over the years confirms this. The correlation coefficient of Global Moran's I using contiguity, inverse distance, border and district based spatial weight matrix are -0.65 , $0.61,-0.61$ and -0.67 respectively and they statistically significant at less than 1 percent level. This implies that a greater spatial dependence across states can help in reducing the inter-state disparity in per capita income. A similar significant correlation of $-0.80,-0.79,-0.86$ and -0.85 is seen for contiguity, inverse distance, border and district based spatial weight matrix respectively at less than 1 percent level in the first sub-phase also though in the second and third sub-phases, the correlation coefficient is not significant.

[Figure 6]

\section{Beta convergence}

Table 4 gives the results of conditional beta convergence models. Annual growth rate of per capita income (NSDP) from agriculture is the dependent variable and explanatory variables are per capita income and other state specific characteristics discussed earlier. Lagged per capita income $(\beta)$ is significant and negative in all the models, indicating statistically significant evidence in favour of beta convergence within Indian states over the entire period 1967-68 to 2010-11. On the basis of loglikelihood, AIC and BIC, spatial models (models 2 - 5) perform better than the non-spatial model (model 1) for the entire period (1967-68 to 2010-11) which confirms the presence of significant spatial dependence in income growth in Indian agriculture.

\footnotetext{
${ }^{10}$ Rey and Montouri (1999) also find a statistically significant positive correlation between standard deviation and Moran's I statistic of per capita income of US.
} 
As literature does not provide much guidance on the spatial weight criteria, the spatial models have been compared on the basis of log-likelihood, AIC and BIC and the contiguous districts based spatial matrix (model 5) performs the best among all other models. This confirms that spatial dependence across states in India is controlled better through contiguous district based spatial weight matrices where higher weight is given to states with more number of contiguous districts. There is a lot of diversity within the states in India and hence often one can find more homogeneity between contiguous districts of neighbouring states compared to non-contiguous districts on the same state. The contiguous-district based spatial weight matrix controls for this spatial homogeneity among neighbouring states. The results however, indicate that the impact of the controlling factors do not vary across different spatial weight models confirming the robustness of the results and estimation strategy.

Results show that spatial spill-over in income from Indian agriculture has occurred through income growth, rural literacy, gross area irrigated and road quality. Spatial income growth is positive and significant for all the models implying that higher growth of a state has positive spill-over effect over its neighbours. In case of contiguity based matrix (model 2), additionally spatial literacy has a positive coefficient implying that states with higher literacy rate have a positive impact over income growth of their neighbours. In case of inverse distance based spatial matrix (model 3), it can be seen that spatial impact is through road quality i.e. higher road quality accelerates growth in neighbouring regions through better connectivity/networking possibilities. Using length of shared borders between states (model 4) and number of contiguous districts (model 5) as weighing criteria, rural literacy, gross area irrigated and road quality have a positive and significant spatial on growth in income among states. Infrastructure therefore has significant spatial dependence across states and aids in growth in neighbouring states.

This finding is in line with studies on other countries like Tong (2012) found significant spatial spill-over through road infrastructure. Similarly there are a number of studies like Patton and McErlean, 2005 on land market, Schmidtner et al (2011) for farming decisions in Germany, which give evidence of significant spatial lag dependence which has often been interpreted as an agglomeration effect and studies 
like Alston (2002) discuss knowledge based channels are discussed in detail and conclude that it as a primary source of spatial spill-over in agriculture. With regard to spatial irrigation, to the best of our knowledge we could not find evidence in existing literature on the plausible reasons for its significant. One possible reason for spatial irrigation to have spill-over effect could be that when neighbouring states receive irrigation investments, especially large surface irrigation projects, its impact does not suddenly stop at the state boundaries. In fact quite often such projects tend to cover several states across multiple agro ecological zones thereby potentially leading to a spatial spill-over across states.

Among inputs, tractors, land and livestock play a statistically significant impact in all the models ${ }^{11}$. Both tractor and land ownership have a positive impact on growth indicating the importance of asset ownership in growth of income. Among livestock, only buffaloes and sheep play a significant role in growth while other forms of livestock remained insignificant and hence were dropped from the analysis. Interestingly, buffaloes have a negative impact on growth in spatial models (insignificant in non-spatial model) while sheep have a positive impact. Livestock not only acts as an input in agriculture production process but also acts as a source of income in the form of wool, meat, milk etc. Although the reason driving the negative relation between buffaloes and growth and insignificant relation between cattle and goats and growth is not very clear, it is possible that these results point towards a non-optimal mix of different types of livestock dominated by bovines ${ }^{12}$.

Results show that infrastructural support in a state has statistically significant impact on its income growth. Key infrastructure like gross area irrigated, villages electrified, road quality and state expenditure on agriculture are significant and positive drivers of growth of income in all the models. Results suggest that higher the infrastructural support in the state more is the income generated from agriculture.

Cropping pattern has been controlled through share of total cropped area under different groups of crops like cereals, pulses, sugar, oil seeds, fibre etc. Share of area under fibre, sugar and oil-seeds are all

\footnotetext{
${ }^{11}$ Fertilizer consumed per unit of cropped area is not significant in any of the models and hence has been dropped from the analysis.

${ }^{12}$ At the all India level, from 1966 to 2007, on an average bovines account for approximately $65 \%$ of all livestock, and within bovines, animals in milk constitute only approximately $35 \%$.
} 
significant and positively influence the growth of income from agriculture ${ }^{13}$. In India, cropping pattern has shown structural rigidity till 1980s when food grains were the dominant crop in India. However, post 1980s, there has been an increase in area under other crop like oil-seeds at the cost of area under pulses and coarse cereals (Bhalla and Singh, 1997). A change in cropping pattern is based on a number of factors like agro-ecological conditions, profitability of crops, availability of technology and infrastructure etc. These results in favour of significant impact of fibre, sugar and oil-seeds support findings from studies like Joshi, Birthal and Minot (2006) which concludes that diversification has been a dominant source of growth since the 1980s in Indian agriculture. The impact of diversification becomes clearer in the next sub-section where we identify the differential impact across the sub-phases.

Human capital has been controlled through rural literacy rate and as expected it has a positive impact on growth of income from agriculture. Deviation of actual rainfall from its normal level greater than 10 per cent significantly reduces growth of income from agriculture in all the models and the impact on income growth is proportional to the level of deviation of actual rainfall from normal.

Table 4- Results of beta convergence

Beta convergence: sub-phases

Comparison of growth process across sub-phases has been done using district based spatial weight matrices in Table 5 since district based spatial weight matrix performed the best across all other spatial weight criteria (Table 4). The results (Table 5) on spatial beta convergence for the sub-phases indicate significant convergence in all the sub-phases.

In the first sub-phase i.e. models 1 and 2, land ownership is the most important income generating input. Fertilizer is significant only if year effects are not controlled (model 1). Among infrastructure, density of surfaced roads is the key growth driving factor in first sub-phase. This phase of green revolution witnessed enormous expansion of area under food-grains especially wheat at the cost of area under other crops and results indicate that share of irrigated area under cereals had a positive impact on income 
growth. However, the area covered under fibre and sugar had negative impact on growth. Spatial rural literacy was a significant driver of growth in this phase. Income growth also had significant spatial dependence as growth in this phase owing to the selective introduction of the new technology was concentrated in certain geographically contiguous states. This phase also witnessed severe to moderate droughts which get reflected in the negative year effects $(1968,1969,1976)$.

In the second sub-phase (model 3), growth was dominated by inputs namely land, tractors and livestock. Among infrastructure, density of surfaced roads again had a significant impact on growth like sub-phase one. Area under cereals like sub-phase one, again led to positive growth. Additionally, area under fibre and oil-seeds also contributed positively to growth. This again validates the findings from studies like Bhalla and Singh (1997) that unprecedented changes took place in the 1980s in cropping pattern and area under other crops expanded at the cost of area under pulses and coarse cereals. Although area under wheat and rice continued to increase in this phase and hence share of area under cereals continue to be a significant driver of growth but one case see that area under other crops were slowly gaining importance in explaining growth of income from agriculture. Excessive rainfall had a negative impact on growth. Spatial growth and irrigation were significant drivers of growth in this phase.

In the third sub-phase (model 4), again land ownership significantly affected income growth. Irrigation contributed in this sub-phase. However, here cereals no longer were a significant driver of growth. Rather in this phase, growth was because of fibre crops. Again this validates the pattern which emerged in studies like Bhalla and Singh (1997) and Joshi, Birthal and Minot (2006) that impact of diversification was highest in the 1990s compared to earlier sub-phases. Literacy was a significant driver of growth in this phase. Spatial spill-over in this phase was because of irrigation and income growth of neighbouring states.

Interesting pattern which comes up from the comparison across sub-phases is the consistent spatial dependence of growth of income and significance of key infrastructure like roads, rural literacy and irrigation across all the sub-phases. Reduction in impact of cropped area under cereals over phases and gaining significance of area under other crops provide evidence in favour of higher returns from 
diversification. Primary driver of growth in the first phase was growth in area under cereals and land ownership while the second phase saw the emergence of impact of mechanization of agriculture and diversification and third phase continued to witness the impact of diversification. Among the spatial factors, rural literacy and irrigation have almost consistently had a significant impact on growth of per capita income in agriculture.

Table 5 -Results of beta convergence for sub-phases

\section{Conclusion}

Growth in income from agriculture has been very different across states in India because of differentials in agro-ecological conditions, cropping pattern, input usage, infrastructural support, yield levels, etc. This despite, Indian agriculture having gone through enormous changes since 1960s when green revolution technology was first introduced. It was initially restricted to certain states where there was well assured irrigation. However, in the next decade, there was diffusion of new technology across other crops and states and hence other states also gained from the new technology. The all India growth rates were highest in the first sub-phase (1966-77) and they declined in the second sub-phase (1978-89) with some revival in the third sub-phase (1990-2010). Coefficient of variation in annual growth across states was highest in the second phase compared to the other sub-phases. States like Punjab and Haryana in the north have always had a higher level of per capita income while states like Bihar and Uttar Pradesh have been always been poor performers. Hence, some pattern of spatial dependence can also be identified where more homogeneity can be seen among neighbouring states. There have also been some instances of catching up over the sub-phases when in the third sub-phase western states like Gujarat and Maharashtra grew at a higher rate than other states. This pattern of persistent inter-state disparity with a spatial pattern and a few instances of catching up provides an empirical basis to analyse the convergence behaviour of per capita income from agriculture taking into account the spatial dependence across states.

Convergence in per capita income in Indian agriculture was analyzed using the two commonly used approaches for analysing convergence namely sigma and beta convergence. Sigma convergence measures 
standard deviation of logarithm of income across states at various time points and they conclude that except in sub-phase one when the standard deviation declined somewhat, there is no evidence of any trend in sigma convergence in any of the other sub-periods / over the entire period.

Beta convergence estimation was also used to test convergence in income from Indian agriculture. Existing literature on beta convergence in Indian agriculture has assumed each state to be an independent and isolated unit. But in reality the performance of neighbouring states can depend on each other due to spatial spill-over. The relative location of states was incorporated econometrically using spatial weight matrices. Apart from conventional state-contiguous, inverse-distance based matrices, district-contiguous and length of state borders shared have also been used in the analysis. These new matrices help to differentiate the impact of two contiguous neighbours as the one with higher number of contiguous districts or length of border shared gets a higher weight in the matrix. This weighing scheme ensures that the incorporated spatial effects are proportional to the possibility of spatial spill-over. Global and local Moran's I tests using these weights found statistically significant spatial dependence across states. Therefore, ignoring relative spatial location in convergence analysis would lead to model misspecification and hence erroneous conclusions.

For spatial convergence analysis, spatially lagged dependent and independent variables were computed using spatial weight matrices. A dynamic fixed effect model was used to correct the autocorrelation problem in panel data. Strong evidence was found in favour of spatial beta convergence in the entire period as well as all the three sub-phases. Spatial convergence models were found to explain the growth pattern better than non-spatial models.

Factors which significantly drove growth in the entire time period were input usage, physical infrastructure and cropping pattern. Interesting pattern which comes up from the comparison across subphases is the consistent spatial dependence of growth of income and significance of key infrastructure like roads, rural literacy and irrigation across all the sub-phases. Reduction in impact of cropped area under cereals over phases and increasing significance of area under other crops provide evidence in favour of higher returns from diversification. Primary drivers of growth in the first phase were growth in area 
under cereals and land ownership while the second phase saw the emergence of impact of mechanization of agriculture and diversification and third phase continued to witness the impact of diversification. Among the spatial factors, rural literacy and irrigation have almost consistently had a significant impact on growth of per capita income in agriculture.

The empirical evidence presented here highlights the importance of inputs and infrastructure in growth in agriculture. Therefore, economic policy measures targeting improvement and expansion of infrastructural support and literacy for example public investments towards irrigation and electricity, roads and rural literacy and input usage can have an important impact in promoting long run agriculture growth and convergence across Indian states.

Some of the limitations of the present study have to be kept in mind while drawing conclusions. A major limitation here is the quality of data availability. It is widely accepted that there is discrepancy in data from government sources on agricultural production, land use etc. because of irregularity of publications and updating the records. Moreover, data on livestock and machinery etc. are not annually available and they had to be interpolated to obtain an annual series. Interpolation potentially might have introduced some errors in the data. Spatial analysis is dependent on spatial weight matrices. Although all the spatial weight matrices gave similar results, there are various other possible definitions of spatial weight matrices like states in the same agro-ecological zones and results might be sensitive to those. Also, there can be other spatial weight criterion which can better control the spatial dependence among states. States in India have huge heterogeneity among the districts in them. Often districts are more homogeneous with contiguous districts of neighbouring states compared to non-contiguous districts of their own states. Capturing the heterogeneity within the states would definitely lead to a better spatial modelling framework. Nevertheless, the results confirm the spatial dependence in Indian agriculture and point towards channels of intervention which can potentially reduce inter-state disparity. 


\section{References}

Abreu, M., De Groot, H. and Florax, J.G.M., 2005. Space and growth: a survey of empirical evidence and methods. Region et development, 21

Alston, J. M., 2002. Spillovers. Australian Journal of Agricultural and Resource Economics. 46, 315346.

Anselin, L., 1988. Spatial Econometrics: Methods and Models. Kluwer Academic, Dordrecht.

Anselin, L., 1995. Local Indicators of Spatial Association-LISA. Geographical Analysis. 27, 93-115.

Barro, Robert and Xavier Sala-I-Martin, 1992. Convergence, Journal of Political Economy 100

Bhalla, G.S. and Singh, G., 1997. Recent Developments in Indian Agriculture: A State Level Analysis. Economic and Political Weekly, 32(13), A2-A18

Binswanger, H.P., Khandker, S., 1993. How infrastructure and financial institutions affect agricultural output and investment in India. Journal of Development Economics, 41(2), 337-366.

Bhalla, G.S. and Singh, G., 1997. Recent Developments in Indian Agriculture: A State Level Analysis. Economic and Political Weekly, 32(13), A2-A18

Bhide, S, Kalirajan, K.P. and Shand, R.T., 1998. India's Agricultural Dynamics: Weak Link in Development, Economic and Political Weekly, 33(39), A118-A127

Chand, R. and Chauhan, S., 1999. Are disparities in Indian agriculture growing? NCAP Policy Brief No. 8 Elhorst, J.P., 2003. Specification and estimation of spatial panel data models. International Regional Science Review, 26(3), 244-268

Elhorst J.P., 2010. Spatial panel data models, in Fischer M.M. and Getis A (Eds) Handbook of applied spatial analysis. pp. 377-407, Berlin, Heidelberg and New York 
Elhorst J.P., 2012. Dynamic spatial panels: Models, methods and inferences. Journal of Geographical Systems 14(1), 5-28

Fan, S., Hazell, P. and Haque, T., 2000. Targeting public investments by agro-ecological zone to achieve growth and poverty alleviation goals in rural India. Food Policy, 25(4), 411-428

Ghosh, M., 2006. Regional convergence in Indian agriculture, Indian Journal of Agricultural Economics 61(4), 610-629.

Jones, R. and Sen, K., 2006. It is where you are that matters: the spatial determinants of rural poverty in India, Agricultural Economics, 34, 229-242

Joshi, P.K., Birthal, P.S. and Minot, N., 2006. Sources of agricultural growth in India: Role of diversification towards high-value crops, IFPRI, MTID Discussion paper No. 98

Lee L.F. and Yu J., 2010. Estimation of spatial autoregressive panel data models with fixed effects, Journal of Econometrics 154(2), 165-185

Lesage, J.P., and Pace, R.K., 2009. Introduction to Spatial Econometrics. New York: Taylor \& Francis/CRC Press, 2009.

Mukherjee, A. and Koruda, Y., 2003. Productivity growth in Indian agriculture: is there evidence of convergence across states? Agricultural economics 29, 43-53

Mukhopadhayay, D. and Sarkar, N., 2014. Convergence of Food grains across Indian states: A study with panel data, Discussion paper Number-03

Patton, M. and McErlean, S., 2003. Spatial Effects within the Agricultural Land Market in Northern Ireland. Journal of Agricultural Economics, 54, 35-54.

Pfaffermayr, M., 2012. Spatial convergence of regions revisited: a spatial maximum likelihood panel approach. Journal of Regional Science, 52, 857-873 
Quah, D. T., 1993a. Empirical Cross-section Dynamics in Economic Growth, European Economic Review, 37, 426-434

Quah, D. T., 1993b. Galton's Fallacy and Tests of the Convergence Hypothesis. Scandinavian Journal of Economics, 95 (4), 427-443

Rey, S. and Montouri, B., 1999. US Regional Income Convergence: A Spatial Econometric Perspective, Regional Studies, 33(2), 143-156

Sala-I-Martin, Xavier, (1994) Cross-sectional regressions and the empirics of economic growth, European Economic Review, 38(3-4), 739-747.

Schmidtner, E., Lippert, C., Engler, B., Häring, A., Aurbacher, J. and Dabbert, S., 2012. Spatial distribution of organic farming in Germany: does neighbourhood matter? European Review of Agricultural Economics, 39(4), 661-683.

Somasekharan, J., Prasad, S. and Roy, N., 2011. Convergence Hypothesis: Some Dynamics and Explanations of Agricultural Growth across Indian States, Agricultural Economics Research Review 24,211-216

Tong, Tingting, 2012. "Evaluating the Contribution of Infrastructure to U.S. Agri-Food Sector Output." Master's Thesis, University of Tennessee.

Wooldridge, J. M., 2005. Simple Solutions to the Initial Conditions Problem in Dynamic, Nonlinear Panel Data Models with Unobserved Heterogeneity. Journal of Applied Econometrics, 20(1), 39-54.

Young A., Higgins, M. and Levy D., 2008. Sigma convergence versus beta convergence: evidence from US county level data, Journal of Money, Credit and Banking 40, 1083-1093 


\section{Figures}

Figure 1: Levels \& growth of NSDP-agri per rural person

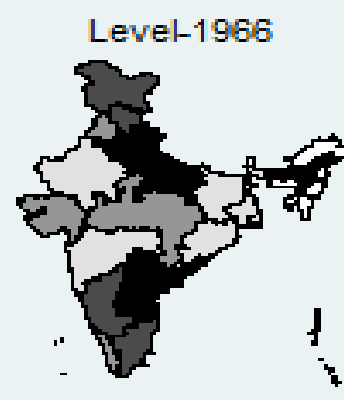

$$
\text { Growth-1966 }
$$

Level-1978

Growth-1978
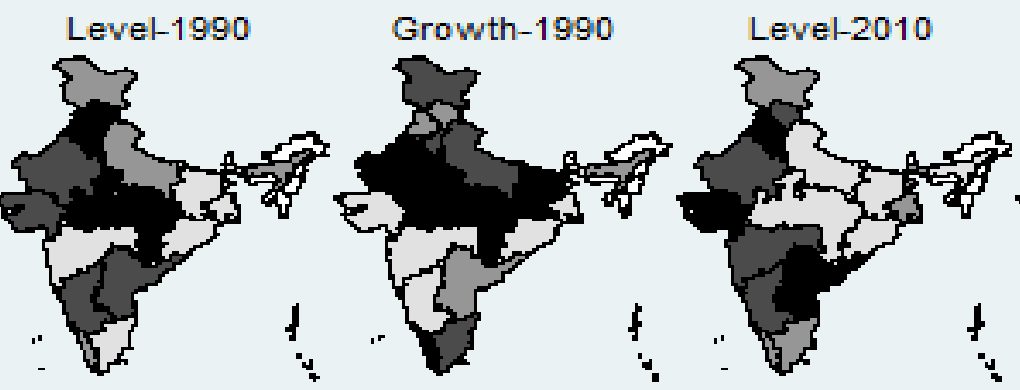

Growth-2010

Darker colour scheme indicates higher growth quantiles and vice versa. 
Figure-2: Share of public GFCF(agri) in GDP(agri)

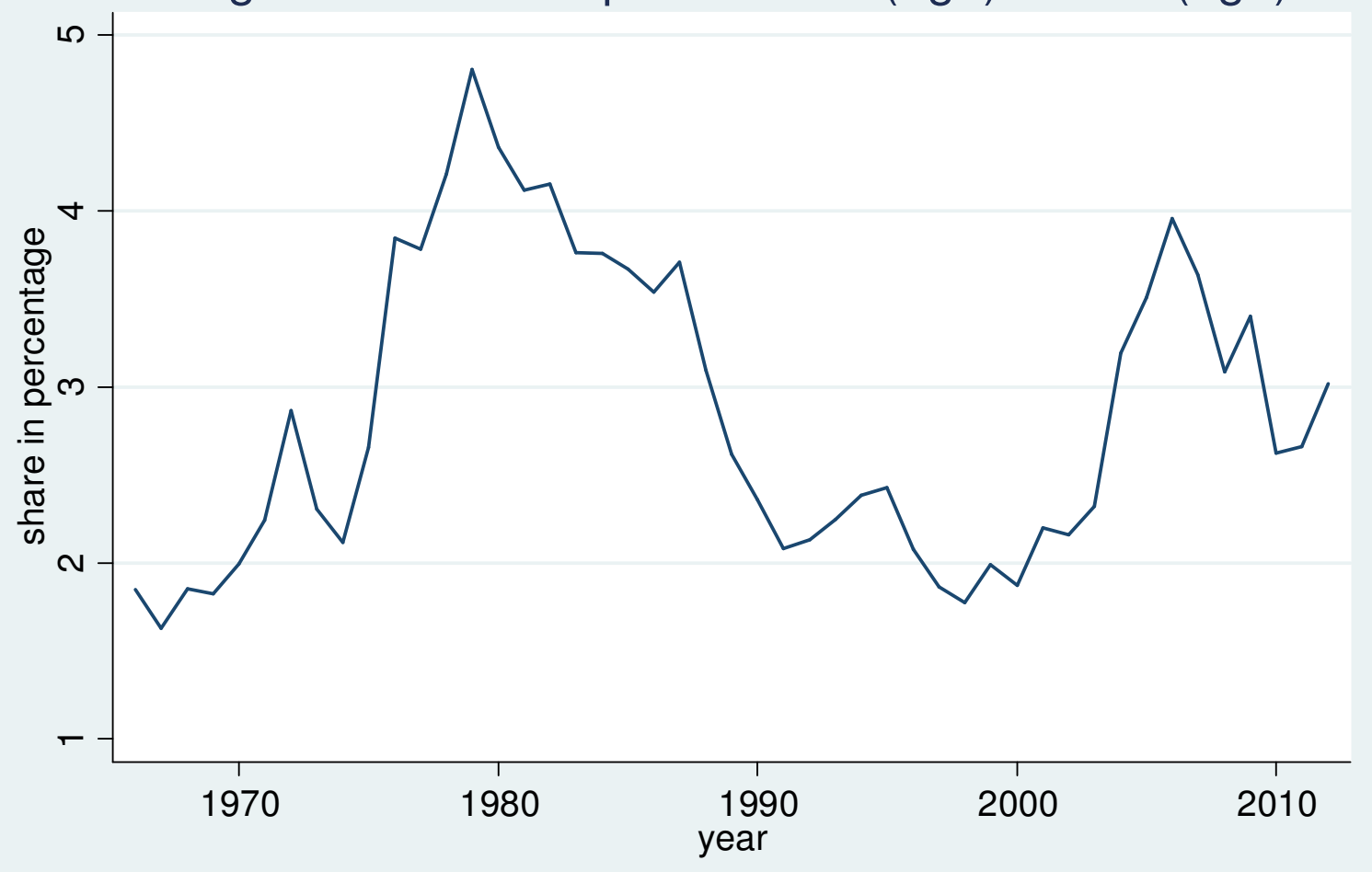

Source: Author's computation 
Figure 3: Inter-state disparity in income and infrastructure

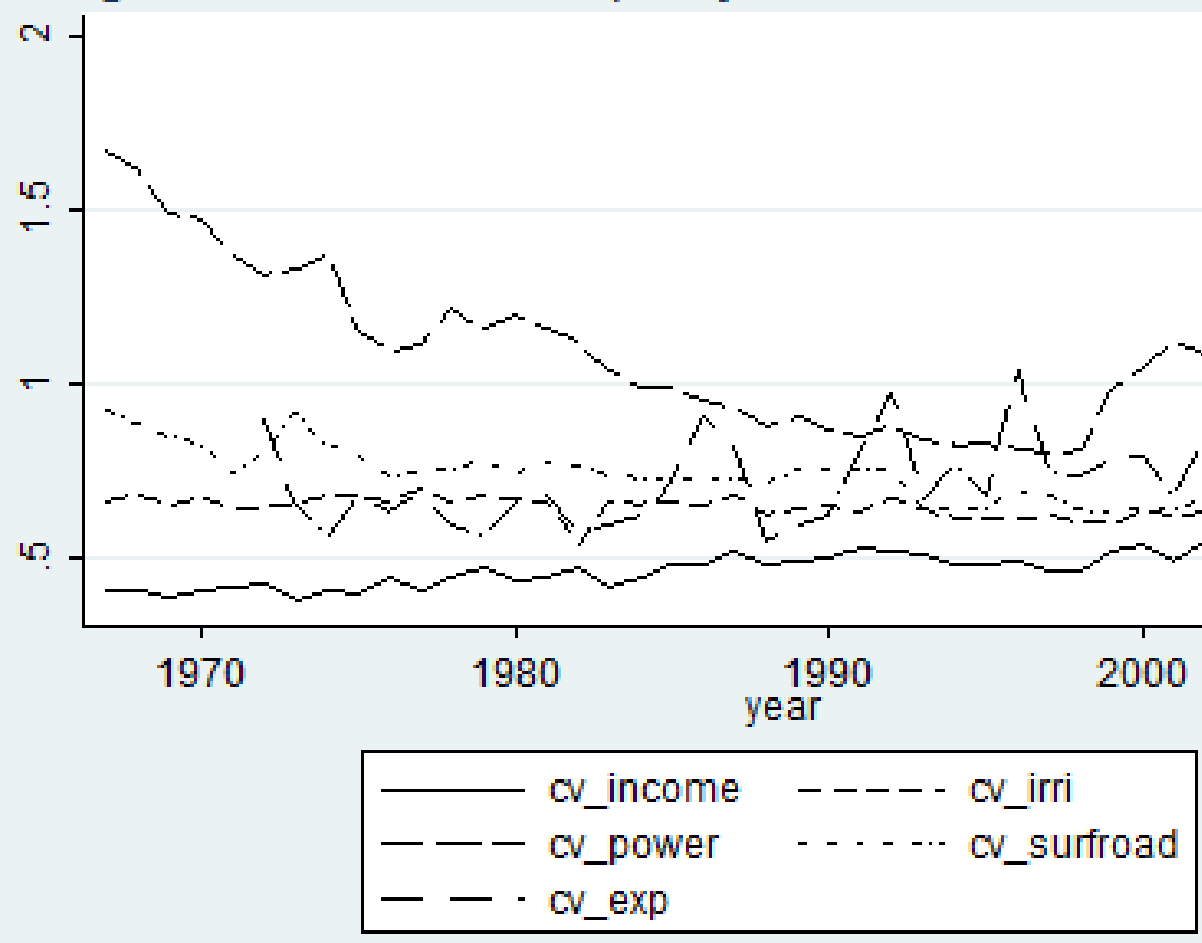

Source: author's computation 
Figure4: Global Moran's I

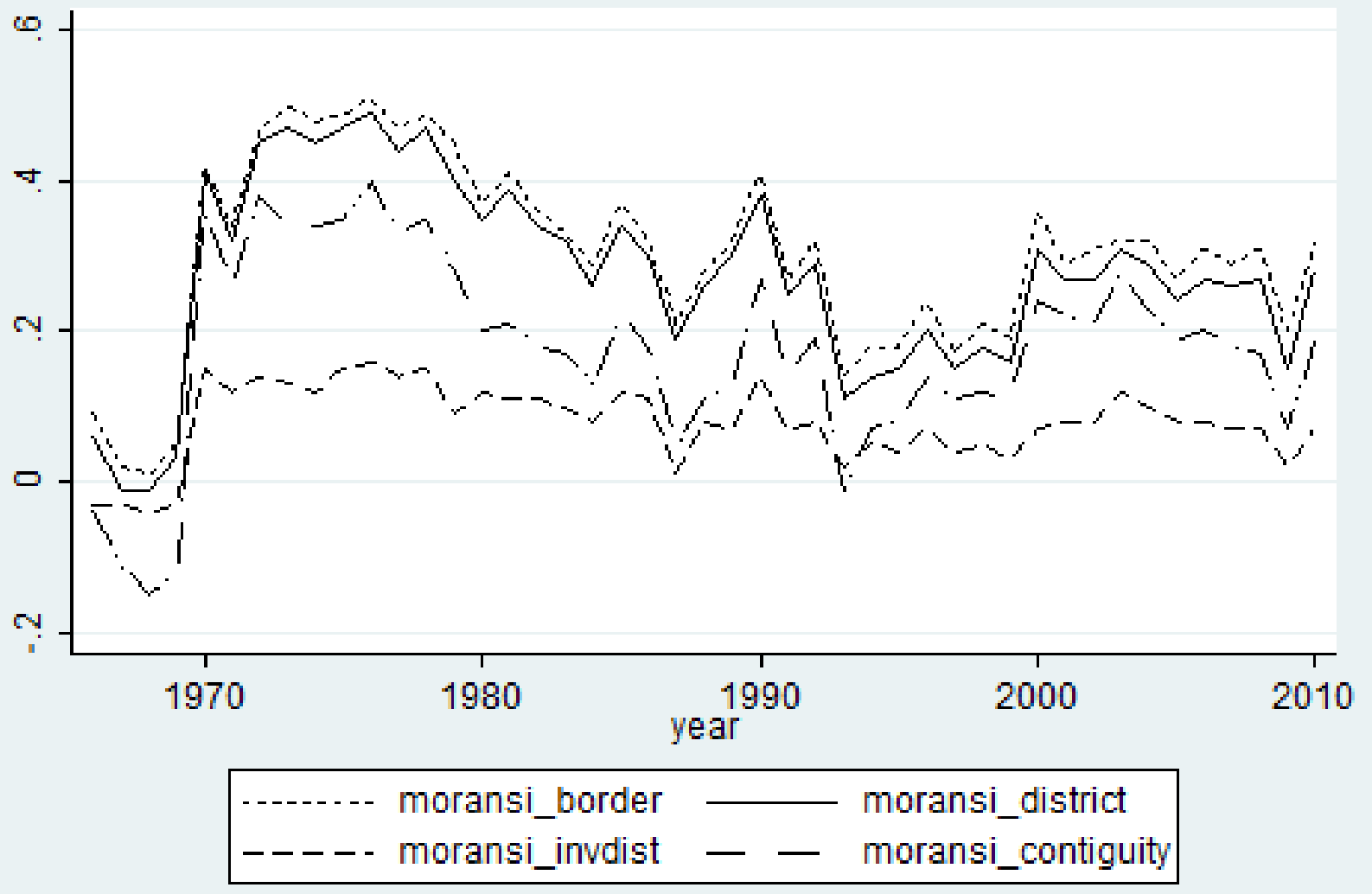


Figure - 5 : Plot of standard deviation in per capita NSDP - agri
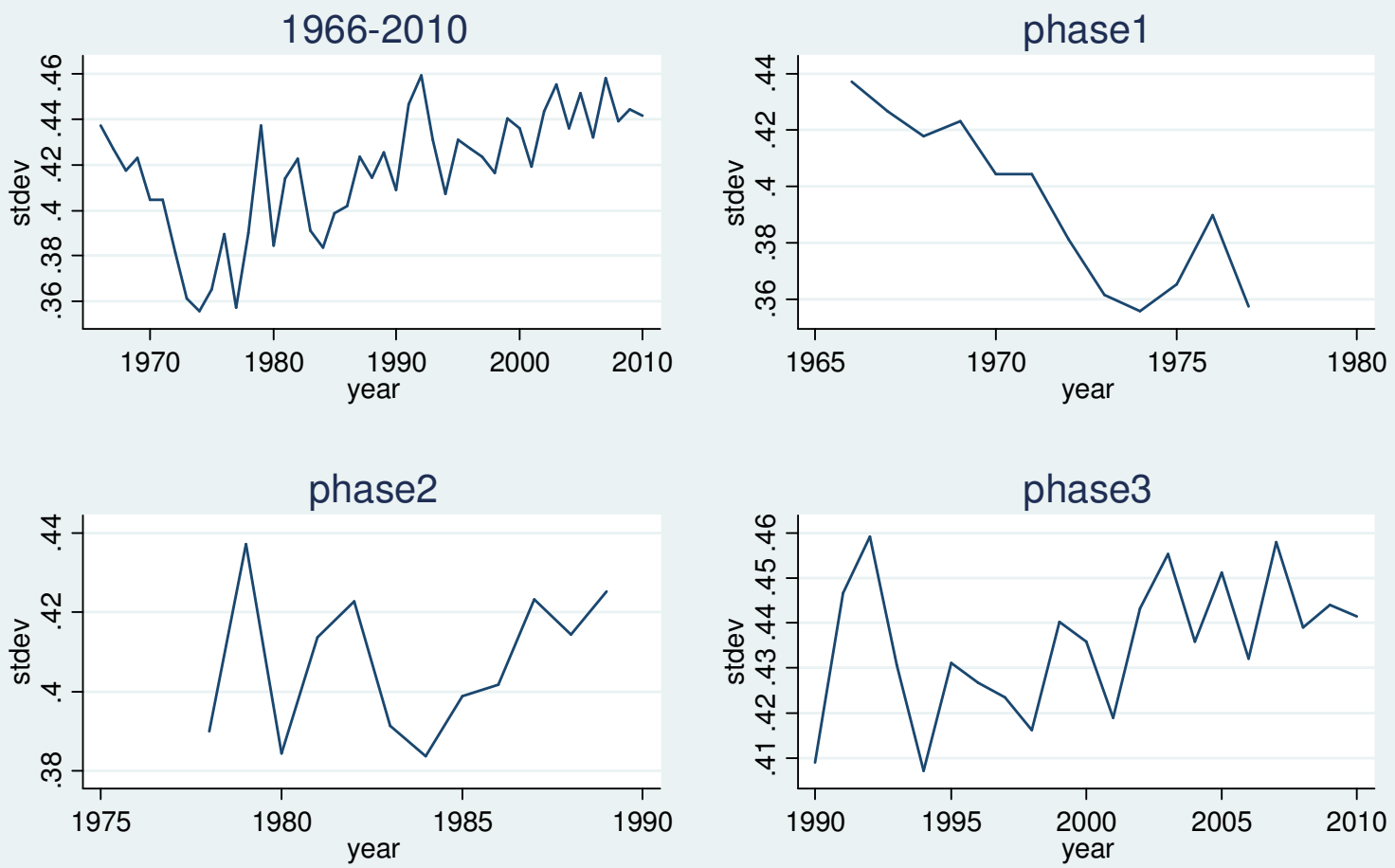

Source : author ' s computation 
Figure 6:Plot of standard deviation and Global Moran's I statistic
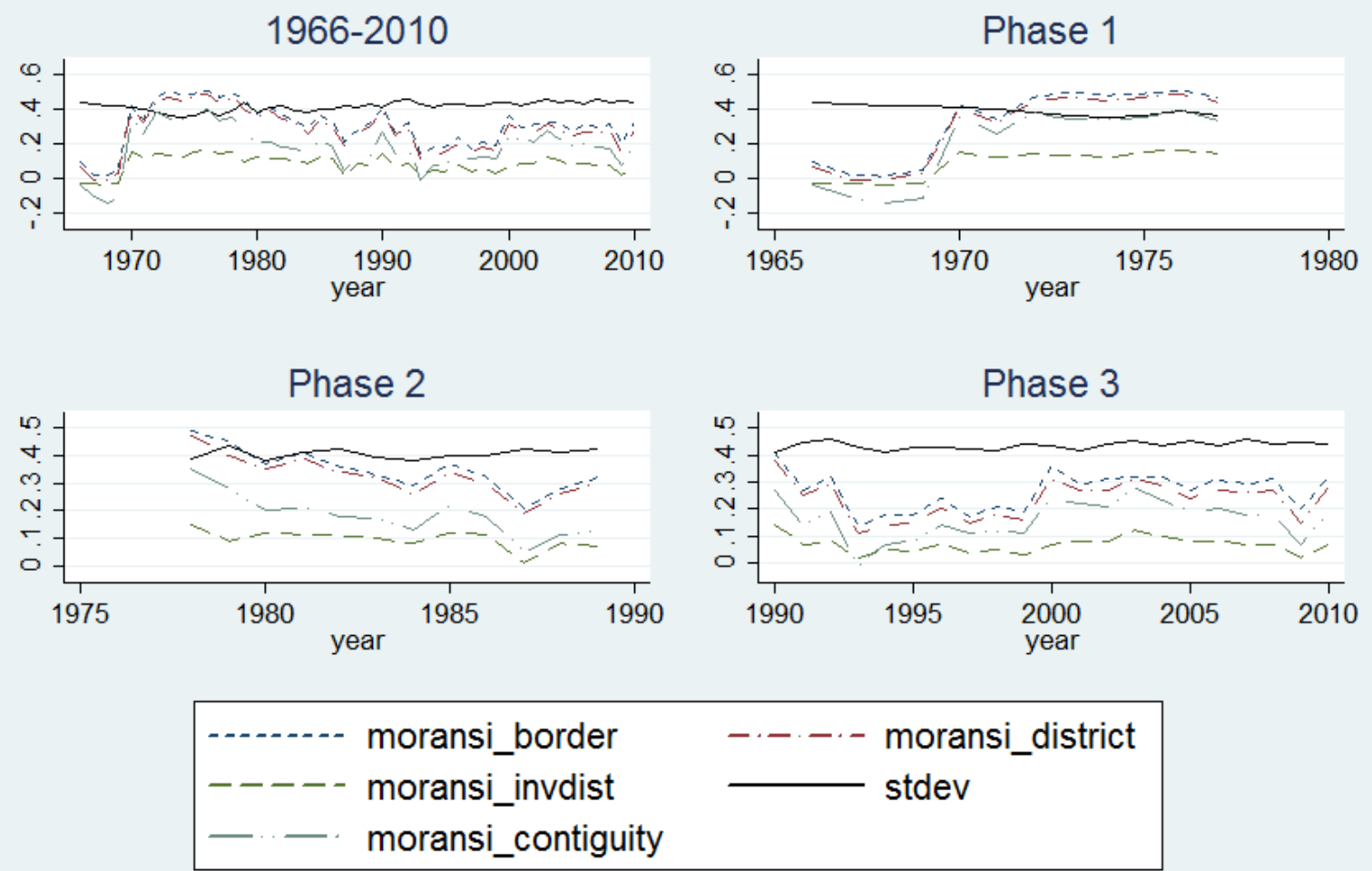


\section{TABLES}

TABLE 1- growth performance across Indian states

\begin{tabular}{lrrrrrrrr}
\hline & \multicolumn{3}{c}{ Income levels } & \multicolumn{5}{c}{ Compound growth rate } \\
\hline State & 1966 & 1977 & 1989 & 2010 & $1966-2010$ & $1966-77$ & $1978-89$ & $1990-2010$ \\
\hline Andhra & 4936 & 5126 & 6421 & 10652 & 1.72 & 0.32 & 1.89 & 2.44 \\
Assam & 4023 & 4592 & 5086 & 5039 & 0.50 & 1.11 & 0.85 & -0.04 \\
Bihar+Jharkhand & 755 & 2483 & 2113 & 2784 & 2.94 & 10.43 & -1.34 & 1.32 \\
Gujarat & 2220 & 6241 & 6491 & 10953 & 3.61 & 9.00 & 0.33 & 2.52 \\
Haryana & 3188 & 9420 & 11487 & 14966 & 3.50 & 9.45 & 1.67 & 1.27 \\
Himachal Pradesh & 2714 & 5627 & 7068 & 7135 & 2.17 & 6.26 & 1.92 & 0.04 \\
Jammu \& Kashmir & 2502 & 5362 & 4840 & 6673 & 2.20 & 6.56 & -0.85 & 1.54 \\
Karnataka & 2922 & 6122 & 6389 & 9159 & 2.57 & 6.36 & 0.36 & 1.73 \\
Kerala & 1875 & 3696 & 4109 & 6859 & 2.92 & 5.82 & 0.89 & 2.47 \\
Maharashtra & 1507 & 3825 & 4605 & 7774 & 3.71 & 8.07 & 1.56 & 2.52 \\
MP+Chhattisgarh & 2238 & 3491 & 5229 & 6145 & 2.27 & 3.78 & 3.42 & 0.77 \\
Orissa & 1668 & 3527 & 6066 & 4945 & 2.44 & 6.44 & 4.62 & -0.97 \\
Punjab & 2195 & 10322 & 14871 & 17950 & 4.78 & 13.77 & 3.09 & 0.90 \\
Rajasthan & 1855 & 4742 & 4889 & 7687 & 3.21 & 8.14 & 0.25 & 2.18 \\
Tamil Nadu & 2467 & 4613 & 4173 & 6913 & 2.32 & 5.35 & -0.83 & 2.43 \\
UP+Uttarakhand & 3091 & 4138 & 4390 & 4874 & 1.02 & 2.46 & 0.49 & 0.50 \\
West Bengal & 1374 & 3794 & 4820 & 7024 & 3.69 & 8.83 & 2.02 & 1.81 \\
\hline India & 2449 & 4615 & 5009 & 6793 & 2.29 & 5.42 & 0.69 & 1.46 \\
\hline CV & 41.30 & 40.04 & 49.22 & 46.77 & 39.26 & 51.75 & 78.37 & 49.87 \\
\hline Source: author's computation & & & & & & & \\
\hline & & & & & & & & \\
\hline
\end{tabular}


TABLE 2: Results of global Moran's test

\begin{tabular}{lcccc}
\hline year & contiguous states & inverse distance & shared-border & contiguous districts \\
\hline 1966 & -0.036 & -0.030 & 0.090 & 0.062 \\
1970 & $0.355^{* * *}$ & $0.153^{* * *}$ & $0.418^{* * *}$ & $0.412^{* * *}$ \\
1978 & $0.351^{* * *}$ & $0.152^{* * *}$ & $0.492^{* * *}$ & $0.468^{* * *}$ \\
1990 & $0.269 * *$ & $0.136^{* * *}$ & $0.412^{* * *}$ & $0.384^{* * *}$ \\
2010 & $0.192^{* *}$ & $0.066^{* *}$ & $0.317^{* *}$ & $0.283^{* *}$ \\
\hline
\end{tabular}

Note: $*$ : $p<0.10 ;^{* *}: p<0.05 ;^{* * *}: p<0.01$ Source: author's estimations. Note: results of other years can be shared on request 
TABLE 3-Results of Local Moran's test

\begin{tabular}{|c|c|c|c|c|c|}
\hline Year & State & Moran's I & Year & State & Moran's I \\
\hline \multicolumn{3}{|c|}{ Contiguity } & \multicolumn{3}{|c|}{ District } \\
\hline 1966 & West Bengal & $0.735^{* *}$ & 1966 & Bihar+Jharkhand & $0.925^{* *}$ \\
\hline 1966 & Bihar+Jharkhand & $0.72^{* *}$ & 1966 & West Bengal & $2.198 * * *$ \\
\hline 2010 & Punjab & $0.747^{* *}$ & 2010 & Haryana & $0.606 *$ \\
\hline \multirow[t]{2}{*}{2010} & Bihar+Jharkhand & $1.389 * * *$ & 2010 & Bihar+Jharkhand & $1.202 * *$ \\
\hline & & & 2010 & Punjab & $1.667 * * *$ \\
\hline \multicolumn{3}{|c|}{ Inverse Distance } & \multicolumn{3}{|c|}{ Border } \\
\hline 1966 & West Bengal & $0.393 * *$ & 1966 & Bihar+Jharkhand & $1.087^{* *}$ \\
\hline 2010 & Assam & $0.164^{* *}$ & 1966 & West Bengal & $2.446 * * *$ \\
\hline 2010 & Orissa & $0.152^{* *}$ & 2010 & Haryana & $0.855^{* *}$ \\
\hline 2010 & Punjab & $0.367^{* *}$ & 2010 & Bihar+Jharkhand & $1.211 * * *$ \\
\hline 2010 & Haryana & $0.399 * *$ & 2010 & Punjab & $1.885^{* * *}$ \\
\hline
\end{tabular}

Note: *: $\mathrm{P}<0.10$; $^{* *}: \mathrm{P}<0.05$; $^{* *}$ : $\mathrm{P}<0.01$ Source: Author's Estimations. Note: Results Of Other Years Can Be Shared On Request 
TABLE 4- Results of beta convergence

\begin{tabular}{|c|c|c|c|c|c|}
\hline \multicolumn{6}{|c|}{ 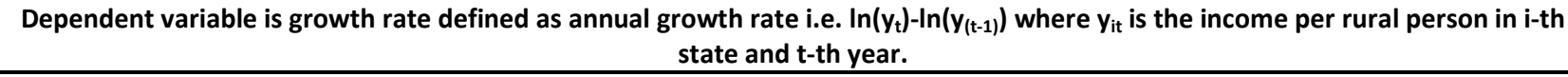 } \\
\hline Variable & non-spatial & contiguity & inverse-distance & shared border & contiguous districts \\
\hline & {$[1]$} & {$[2]$} & {$[3]$} & {$[4]$} & {$[5]$} \\
\hline lagged income & $-0.623^{* * *}(0.094)$ & $-0.627^{* * *}(0.074)$ & $-0.625^{* * *}(0.083)$ & $-0.625^{* * *}(0.071)$ & $-0.624 * * *(0.069)$ \\
\hline lagged growth & $-0.197 * * *(0.032)$ & $-0.162 * * *(0.028)$ & $-0.167^{* * *}(0.027)$ & $-0.163 * * *(0.028)$ & $-0.160 * * *(0.028)$ \\
\hline per capita tractor & $0.959 * * \quad(0.340)$ & $1.304^{* * *}(0.398)$ & $1.241 * * *(0.296)$ & $1.378^{* * *}(0.361)$ & $1.359 * * *(0.377)$ \\
\hline $\begin{array}{l}\text { per capita land } \\
\text { buffaloes per sq. } \\
\text { km. }\end{array}$ & $2.060 * * *(0.380)$ & $-0.167^{* *}(0.076)$ & $-0.123 *(0.063)$ & $-0.183^{* *}(0.085)$ & $-0.178^{* *}(0.085)$ \\
\hline sheep per sq. km. & $0.153^{* * *}(0.038)$ & $0.122^{* * *}(0.041)$ & $0.106 * * *(0.036)$ & $0.139 * * *(0.039)$ & $0.134 * * *(0.032)$ \\
\hline irrigation & $0.121 * * *(0.030)$ & $0.113 * * *(0.023)$ & $0.119 * * *(0.029)$ & $0.126 * * *(0.023)$ & $0.127^{* * *}(0.023)$ \\
\hline $\begin{array}{l}\text { village electricity } \\
\text { dummy }\end{array}$ & $-0.053^{* *}(0.020)$ & $-0.058 * * *(0.021)$ & $-0.034 *(0.021)$ & $-0.054 * * *(0.020)$ & $-0.055 * * *(0.019)$ \\
\hline road quality & $0.154 * \quad(0.084)$ & $0.110 *(0.064)$ & $0.135^{* *}(0.065)$ & $0.126 * *(0.052)$ & $0.122^{* *}(0.052)$ \\
\hline agri exp per area & $0.003 * *(0.001)$ & $0.003 * * *(0.001)$ & $0.002 * *(0.001)$ & $0.003 * * *(0.001)$ & $0.003 * * *(0.001)$ \\
\hline share of oil & $1.105^{* * *}(0.168)$ & $1.107^{* * *}(0.186)$ & $0.999 * * *(0.188)$ & $1.041 * * *(0.172)$ & $1.033^{* * *}(0.173)$ \\
\hline share of fibre & & $0.915^{* * *}(0.322)$ & $0.846 * *(0.383)$ & $0.923 * * *(0.335)$ & $0.906 * * *(0.328)$ \\
\hline share of sugar & $2.948 * \quad(1.469)$ & $3.139 * *(1.274)$ & $2.989 * *(1.262)$ & $2.835^{* *}(1.255)$ & $2.926 * *(1.221)$ \\
\hline rural literacy & $0.009 * * *(0.002)$ & $0.004 *(0.002)$ & $0.006^{* * *}(0.002)$ & $0.004 *(0.002)$ & $0.004 *(0.002)$ \\
\hline rain dummy 2 & $-0.014 * *(0.006)$ & $-0.014 * *(0.007)$ & $-0.014 * *(0.006)$ & $-0.012 *(0.007)$ & $-0.012 *(0.007)$ \\
\hline rain dummy 3 & $-0.042^{* * *}(0.013)$ & $-0.040 * * *(0.012)$ & $-0.040 * * *(0.012)$ & $-0.039 * * *(0.012)$ & $-0.039 * * *(0.012)$ \\
\hline $\begin{array}{l}\text { spatial rural } \\
\text { literacy }\end{array}$ & & $0.006 * * *(0.001)$ & & $0.003^{* *}(0.002)$ & $0.003^{* *}(0.002)$ \\
\hline $\begin{array}{l}\text { spatial irrigation } \\
\text { spatial road } \\
\text { quality }\end{array}$ & & & $0.685^{* * *}(0.215)$ & $0.101 * * *(0.037)$ & $\begin{array}{l}0.094 * * *(0.036) \\
0.160 * *(0.072)\end{array}$ \\
\hline spatial growth & & $0.267^{* * *}(0.044)$ & $0.319 * * *(0.062)$ & $0.258^{* * *}(0.044)$ & $0.273 * * *(0.047)$ \\
\hline \multicolumn{6}{|c|}{ STATISTICS } \\
\hline No. of observation & 663 & 646 & 646 & 646 & 646 \\
\hline log-likelihood & 587.857 & 607.532 & 602.566 & 612.487 & 615.42 \\
\hline AIC & -1147.713 & -1183.065 & -1173.131 & -1192.973 & -1198.84 \\
\hline $\mathrm{BIC}$ & -1084.758 & -1111.532 & -1101.599 & -1121.44 & -1127.307 \\
\hline R-square & 0.525 & 0.567 & 0.565 & 0.571 & 0.573 \\
\hline
\end{tabular}


TABLE 5 -Results of beta convergence for sub-phases

Dependent variable is annual growth rate i.e. $\ln \left(y_{t}\right)-\ln \left(y_{(t-1)}\right)$ where $y_{i t}$ is the income per rural person in i-th state and $t$-th year.

\begin{tabular}{|c|c|c|c|c|}
\hline \multirow[t]{2}{*}{ Variable } & phase1 & phase 1 & phase2 & phase3 \\
\hline & [1] & {$[2]$} & [3] & {$[4]$} \\
\hline Time lagged income & $-0.402 * * *(0.045)$ & $-0.409 * * *(0.030)$ & $-0.940 * * *(0.110)$ & $-0.582^{* * *}(0.059)$ \\
\hline \multicolumn{4}{|l|}{ Time lagged growth } & $-0.211 * * *(0.046)$ \\
\hline Fertilizer per sq. km. & $0.125^{* *}(0.056)$ & & & \\
\hline per capita land & $1.369 * * *(0.316)$ & $1.658 * * *(0.246)$ & $2.813^{* * *}(0.413)$ & $1.759 * * *(0.322)$ \\
\hline \multicolumn{3}{|l|}{ per capita tractor } & $2.268^{* *}(1.025)$ & \\
\hline \multicolumn{3}{|l|}{ livestock per sq. km } & $0.130 * * *(0.047)$ & \\
\hline surf. Road per sq. km & $0.060 * *(0.028)$ & $0.074 * *(0.029)$ & $0.102 * * *(0.024)$ & \\
\hline \multicolumn{4}{|l|}{ gross irri per sq. km. } & $0.176 * * *(0.044)$ \\
\hline \multicolumn{5}{|l|}{ share of cereals } \\
\hline \multicolumn{2}{|l|}{ share of pulses } & $1.959 * *(0.913)$ & & \\
\hline share of fibre & $-3.212 * *(1.403)$ & $-3.012 * *(1.348)$ & $1.303^{* *}(0.646)$ & $0.903 * * *(0.344)$ \\
\hline share of sugar & $-6.979 * * *(2.676)$ & & & \\
\hline \multicolumn{3}{|l|}{ share of oil } & $1.707 * *(0.750)$ & \\
\hline rural literacy & $0.006 * * *(0.002)$ & $0.006 * *(0.002)$ & & $0.007 * * *(0.002)$ \\
\hline \multicolumn{3}{|l|}{ rain dummy_3 } & $-0.074^{* * *}(0.020)$ & \\
\hline spatial rural literacy & $0.011^{* * *}(0.004)$ & $0.016 * * *(0.004)$ & & \\
\hline \multicolumn{3}{|l|}{ spatial irrigation } & $0.465 * * *(0.148)$ & $0.201 * * *(0.065)$ \\
\hline spatial growth & $0.547 * * *(0.070)$ & $0.176 * *(0.087)$ & $0.150 * * *(0.048)$ & $0.218 * * *(0.076)$ \\
\hline \multirow[t]{2}{*}{ year effects } & NO & YES & YES & YES \\
\hline & & STATISTICS & & \\
\hline \multicolumn{2}{|l|}{ No of observations } & 170 & 187 & 340 \\
\hline \multicolumn{2}{|l|}{ Pseudo-log likelihood } & 98.944 & 197.183 & 356.437 \\
\hline \multicolumn{2}{|r|}{-132.899} & -169.888 & -364.367 & -688.874 \\
\hline \multicolumn{2}{|r|}{-98.405} & -125.987 & -315.9 & -642.926 \\
\hline \multicolumn{2}{|l|}{ R-sq. } & 0.696 & 0.753 & 0.55 \\
\hline
\end{tabular}

